\title{
Tetrabutylammoniumbromide mediated Knoevenagel condensation in water: synthesis of cinnamic acids
}

\author{
Monika Gupta ${ }^{\mathrm{a} *}$ and Basant Purnima Wakhloo ${ }^{\mathrm{b}}$ \\ ${ }^{a}$ Department of Chemistry, University of Jammu, Jammu-180 006, India \\ ${ }^{b}$ NMR Instrumentation Section, Regional Research Laboratory, Jammu-180 001, India \\ E-mail: monika.gupta77@,rediffmail.com
}

\begin{abstract}
A simple, mild and environment-friendly procedure has been developed for Knoevenagel condensation between aromatic aldehydes or ketones and malonic acid in the presence of tetrabutylammoniumbromide and $\mathrm{K}_{2} \mathrm{CO}_{3}$ under microwave irradiation in water. The products are obtained in excellent yields and are in a state of high purity.
\end{abstract}

Keywords: Knoevenagel condensation, carbonyl compounds, malonic acid, phase transfer catalyst, cinnamic acids, microwave activation

\section{Introduction}

Many chemical processes employ large amounts of hazardous and toxic solvents. The choice of pursuing aqueous reactions is becoming more important and urgent than ever before, due to its environmental impact and cost of chemical processes. Organic reactions under solvent-free ${ }^{1,2}$ and aqueous $^{3-5}$ conditions have increasingly attracted chemists interests, particularly from the view point of green chemistry. ${ }^{6}$ Knoevenagel condensation of malonic acid and carbonyl compounds is an important route for substituted $\alpha, \beta$-unsaturated acids and the method of choice particularly for cinnamic acids is through Doebner modification. ${ }^{7,8}$ This involves heating of aromatic aldehydes and malonic acid in the presence of excess of basic solvents like pyridine and piperidine to facilitate easy decarboxylation of initially generated $\alpha, \beta$-unsaturated malonic acids which afford cinnamic acids. There has been a number of reports ${ }^{9}$ on the condensation of carbonyl substrates with a variety of active methylene compounds using inorganic catalysts, traditional bases both under conventional as well as microwave heating conditions. Very few Knoevenagel condensations using water as solvent have been reported. ${ }^{10,11}$ However, no reaction utilizing water as solvent has been reported for the synthesis of cinnamic acids.

In recent years, MW activation coupled with phase transfer catalysis ${ }^{12}$ using water has emerged as a highly efficient and environment-friendly methodology as on cooling, products are 
separated out and are generally in a state of high purity. Further, work-up procedure is simply reduced to filtration followed by washing with water.

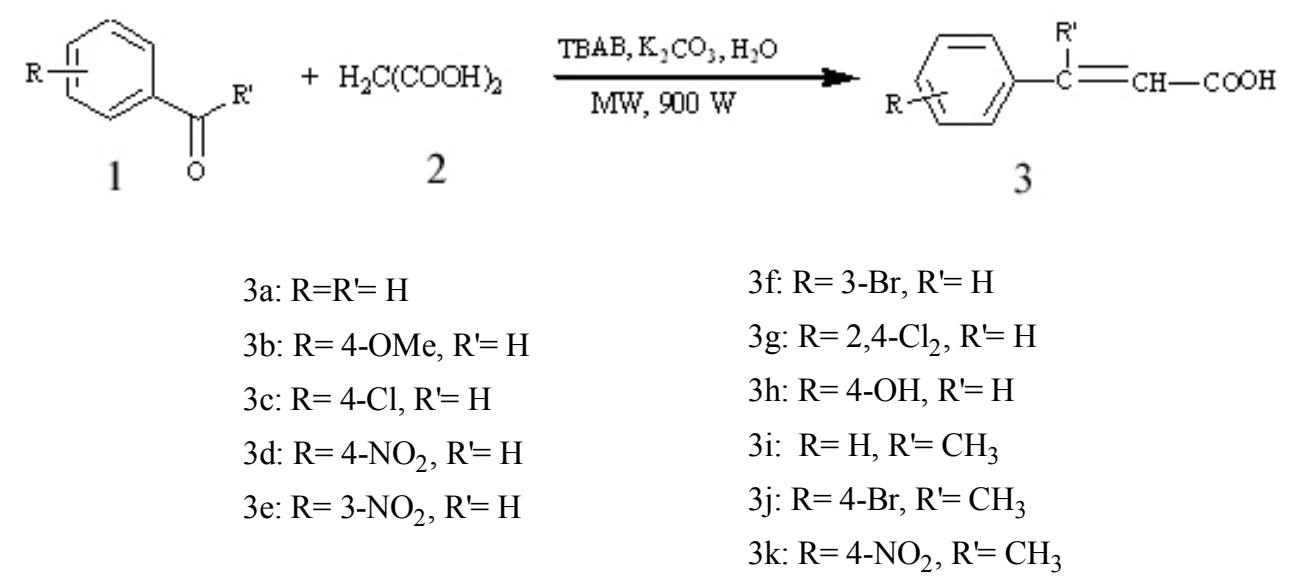

\section{Scheme 1}

\section{Results and Discussion}

In this paper, we wish to report an environment-friendly procedure for Knoevenagel condensation between aldehydes or ketones and malonic acid in the presence of tetra butyl ammonium bromide and $\mathrm{K}_{2} \mathrm{CO}_{3}$ under microwave irradiation using water as an energy transfer medium.

Valizadeh et al. has reported ${ }^{11}$ the reaction between aldehydes and malonic acid using $\mathrm{NH}_{4} \mathrm{Cl}$ and water under MW irradiation but the products obtained are $\alpha, \beta$-unsaturated malonic acids i.e. reaction stops before decarboxylation. Our developed method involves the irradiation of a mixture of aromatic aldehyde or ketone with malonic acid using TBAB, $\mathrm{K}_{2} \mathrm{CO}_{3}$ and water. As soon as irradiation is stopped and after few minutes of cooling followed by acidification with dil. $\mathrm{HCl}$, cinnamic acids are separated out which are of high purity. For instance, in case of product 3a, Table 1, when a mixture of benzaldehyde $(5 \mathrm{mmol})$, malonic acid $(5 \mathrm{mmol})$, TBAB (2.5 $\mathrm{mmol}), \mathrm{K}_{2} \mathrm{CO}_{3}(2.5 \mathrm{mmol})$ and distilled water $(10 \mathrm{~mL})$ was heated under microwaves for 5 minutes at $900 \mathrm{~W}$, cinnamic acid was isolated as a pure product (TLC) in $85 \%$ yield. So within 5 minutes, Knoevenagel condensation as well as decarboxylation of corresponding $\alpha, \beta$-unsaturated malonic acid took place and the compound isolated was cinnamic acid. The method is equally efficient in case of acetophenone (3i, Table 1, time $6 \mathrm{~min}$, yield 86\%). The method is then extended for other aromatic aldehydes as well as acetophenones substituted with electrondonating and electron-withdrawing groups. The results are given in Table 1. 
Table 1. Microwave-assisted tetra butyl ammonium bromide mediated synthesis of cinnamic acids using $\mathrm{K}_{2} \mathrm{CO}_{3}$ and water (power $=900 \mathrm{~W}$ )

\begin{tabular}{cccc}
\hline Product $^{\mathrm{a}}$ & Time $^{\mathrm{b}}(\mathrm{min})$ & Yield $^{\mathrm{c}}(\%)$ & M.p./lit.m.p. $\left({ }^{\circ} \mathrm{C}\right)$ \\
\hline $\mathbf{3 a}$ & 5 & 85 & $130-132 / 133^{13}$ \\
$\mathbf{3 b}$ & 6 & 65 & $169-170 / 170-173^{13}$ \\
$\mathbf{3 c}$ & 5 & 80 & $245-247 / 248^{13}$ \\
$\mathbf{3 d}$ & 5.5 & 75 & $285-287 / 289^{13}$ \\
$\mathbf{3 e}$ & 3.5 & 80 & $199-200 / 202^{13}$ \\
$\mathbf{3 f}$ & 4 & 70 & $169-170 / 170^{13}$ \\
$\mathbf{3 g}$ & 4.5 & 73 & $229-230 / 230^{13}$ \\
$\mathbf{3 h}$ & 5.5 & 72 & $213-214 / 214^{13}$ \\
$\mathbf{3 i}$ & 6 & 86 & $116-117 / 115-116^{14}$ \\
$\mathbf{3 j}$ & 5.5 & 85 & $116-117 / 117^{15}$ \\
$\mathbf{3} \mathbf{k}$ & 8 & 90 & $167-168 / 168^{16}$ \\
\hline
\end{tabular}

${ }^{a}$ All products were identified by IR, ${ }^{1} \mathrm{H}$ NMR and mass spectral data and comparison of melting point with authentic samples available commercially or prepared according to the reported methods.

${ }^{\mathrm{b}}$ Reactions were carried out with pulse of $5 \mathrm{~s}$ with $10 \mathrm{~s}$ cooling time due to evolution of carbon dioxide.

${ }^{\mathrm{c} I s o l a t e d ~ y i e l d . ~}$

\section{Experimental Section}

General Procedures. Melting points were determined on a Perfit melting point apparatus and are uncorrected. The reactions were monitored by TLC. For the microwave irradiation experiments described below, a conventional (unmodified) household microwave oven equipped with a turntable was used (LG Smart Chef MS-255R operating at $2450 \mathrm{MHz}$ having maximum output of $900 \mathrm{~W})$.

\section{General procedure for the synthesis of cinnamic acids by Knoevenagel condensation between carbonyl compounds and malonic acid}

To a mixture of aromatic aldehyde or ketone $(5 \mathrm{mmol})$, malonic acid $(5 \mathrm{mmol}$ in case of aldehyde and $10 \mathrm{mmol}$ for ketone), $\mathrm{TBAB}(2.5 \mathrm{mmol})$ and $\mathrm{K}_{2} \mathrm{CO}_{3}(2.5 \mathrm{mmol})$ in a borosil beaker $(50 \mathrm{~mL})$, distilled water $(10 \mathrm{~mL})$ was added. The reaction mixture was mixed properly with the help of a glass rod $(5 \mathrm{~s})$ and irradiated in a microwave oven at $900 \mathrm{~W}$ for an appropriate time (monitored by TLC, Table 1). On cooling and acidification with dil. $\mathrm{HCl}$, the product was isolated by filtration followed by washing with water. It was pure enough and further purified by crystallization from EtOAc: pet. ether or EtOH for carrying out spectral analysis. 
The structures of the products were confirmed by ${ }^{1} \mathrm{H}$ NMR, IR, mass spectral data and by comparison with authentic samples available commercially or prepared according to literature methods.

\section{Conclusions}

In conclusion, we have developed a rapid, economic and environment-friendly method for the synthesis of cinnamic acids by Knoevenagel condensation between aldehydes or ketones and malonic acid in the presence of $\mathrm{TBAB}, \mathrm{K}_{2} \mathrm{CO}_{3}$ and distilled water. The main advantage of our method is that it is general and also no organic solvent or reagent was used throughout the reaction.

\section{Acknowledgements}

One of the authors (M.G.) is thankful to the Council of Scientific and Industrial Research (CSIR), New Delhi, for awarding Senior Research Fellowship (SRF).

\section{References}

1. Tanaka, K.; Toda, F. Chem. Rev. 2000, 100, 1025.

2. Loupy, A. Top Cur. Chem. 1999, 206, 153.

3. Li, C-J.; Chan, T-H. Reactions in Aqueous Media, John Wiley \& Sons: New York, 1997.

4. Grieco, P. A., Ed.; Organic Synthesis in Water; Blackie Academic and Professional: London, 1998.

5. Lubineau, A; Augé, J. Top Cur. Chem. 1999, 206, 1.

6. Anastas, P. T.; Warner, J. C. Green Chemistry: Theory and Practice, Oxford University Press: Oxford, 1998.

7. Jones, G. Knoevenagel Condensation in Organic Reaction, Wiley: New York, 1967, Vol. 15, p 204.

8. Trost, B. M. Comprehensive Organic Synthesis; Pergamon Press: Oxford, 1991, Vol. 2, p 341.

9. (a) Lehnert, W. Synthesis 1974, 667. (b) Rao, P. S.; Venkataratnam, R. V. Tetrahedron Lett. 1991, 32, 5821. (c) Prajatapti, D.; Sandhu, J. S. J. Chem. Soc. Perkin Trans. 1, 1993, 739.

(d) Texier-Boulett, F.; Foucaod, A. Tetrahedron Lett. 1982, 23, 4927. (e) Cabello, J. A.; Campelo, J.M.; Garcia, A.; Luna, D.; Marinas, J. M. J. Org. Chem. 1984, 41, 5195. (f) Reddy, T. I.; Varma, R. S. Tetrahedron Lett. 1997, 38, 1721. (g) Wang, Q. L.; Yudao, Ma.; Zua, B. Synth. Commun. 1997, 27, 4107. (h) Ayoubi, S.; Abdallah-EI.; Texier-Boullet, F.; 
Hamelin, J. Synthesis 1994, 258. (I) Cruz, P. de. La.; Diez-Barra, E.; Loupy, A.; Langa, F. Tetrahedron Lett. 1996, 37, 1113. (j) Mogilaiah, K.; Reddy, G. R. Synth. Commun. 2004, 34, 205.

10. Bigi, F.; Conforti, M. L.; Maggi, R.; Piccinno, A.; Sartori, G. Green Chem. 2000, 2, 101.

11. Valizadeh, H.; Mamaghani, M.; Badrian, A. Synth. Commun. 2005, 35, 785.

12. See review: Deshayes, S.; Liagre, M.; Loupy, A.; Luche, J-L.; Petit, A. Tetrahedron 1999, $55,10851$.

13. Aldrich catalog handbook of fine chemicals 2005-2006.

14. Stevens, R. Dictionary of Organic Compounds, $4^{\text {th }}$ Edn., Eyre and Spottiswoode: London, 1971.

15. Psarrea, Bull. Soc. Chim. Fr. 1961, 2152.

16. Baker, B. R.; Lourens, G. J. J. Med. Chem. 1968, 11, 672. 